p. 600) quotes Diez as having found, among other symptoms, that ergot given to dogs caused " semiparalysis of the extremities, especially of the hinder ones ;" and Gaspard as having found that an intravenous injection of aqueous extract produces in the same animal "paralysis of the posterior extremitics." In a recent communication, Dr. Althaus (Bkitish MkDical JourNal, May 10th, 1884, p. 893) says, "Bread contaminated with ergot of rye will, when habitually taken for some tinie, cause well marked decrease of the posterior columns." Kobert (lov: cit., p. 21) found that eighty grammes of ergot, giren to a pig with oil and milk, caused it to become, in three days, markedly ataxic, with loss of the patellar reflex.

With these facts before us, pointing as they do to the possibility of ergot inducing such a formidable disease as locomotor ataxy, or, at any rate, ataxic symptoms, the importance of being cautious in pre. scribing this drug for any length of time is obvious. Without venturing any pronounced opinion, either upon the pathology or upon the etiology of this disoase, there are many cases of it which occur to us in actual practice in which none of the usually accredited causes, such as syphilis, sexual excess, alcoholic abuse, exposure to cold, etc., can be blamed. Although rye-bread is not consumed in this country as an article of diet to any extent, yet one class of the community, at any rate, is liable to ergotisation from a source which is not generally recognised.

In many parts of England, especially in the oastern counties, wheat is often ergoted to aii extent, in some seasons, that wonld hardly be credited by anyone who has not specially looked into the matter. This being the case, a few remarks upon the subject may not be ont of place.

Of all our cereal crops, ryc is most subject to ergot, next to it wheat, very rarely barley, and never, as far as my knowledgo gocs, oats. Many species of grasses are, however, ercoted to an extent that is of very serious import to the graziers. In all these cases, the same fungus is tho cause (Claviceps purpurea)

An ergot is an ovule of one of these grassos into which, either at the time of its fecundation by the pollen, or immediately afterwards, a spore of the Claviceps has gained admission. Tho spore once inside, gives rise to mass of mycclium, which so alters the grain that, instead of developing into starch, it becomes a sclerotium, or, in other words, a consolidated mass of mycolium, which remains in a state of yuiescence for a long time (one or two years if necessary), but retaining its vitality until favourable conditions enable it to produce the perfect fungus, Claviceps. This, under ordinary circumstances, takes placo in May and June, just about the time that the grasses and cereals sre in flower. The spores of the Claviceps come into contact with the stigma of the grass by being carried in the air to it, and then give rise in the ovule, not directly to an ergot, but to an enormous number of very minute spores (conidia), which are held together, by a viscid material, into a mass to which the name sphacelia has been applied. It is obvious that these conidia (which used to bo called Ergotetia abortifaciens), held together as they are by the sticky material, cannot be blown from one plant to another by any wind-currents.

Flückiger (Lehrbuch der Pharkognosic des Pflanzenrciches: Borlin, 1867) has shown that the viscid substance in the sphacelia is saccharine, and produces a copious precipitate of the suboxide of copper with Yehling's solution; and Ráthay (Untersuchungen über dic Spermogonicn der Rostpilze, Wien, 1882, p. 35) says that eighteen species of Diptera, as well as other insects, visit the sphacelia in search of their sugary pabulum, and thus convey the conidia to healthy stigmata, in the same way as other insects in their search for the honey of flowering plants carry the pollen from flower to flower. Subsequently, the production of conidia ceases, and the truc ergot is developed by the infected ovule, and so the life-cycle of the fungus is maintained throughout the year.

Mr. A. Stephen Wilson informs me, however, that, while he has eonfirmed Ráthay's observation as to the a vidity with which insects, especially flies, feed upon the sphacelia, yet they die in great numbers, apparently poisoned by it.

The reproduction of the fungus by means of the conidia continues on some species of grass throughout the summer and antumn. Notably is this the case with the common rye-grass (Lolium perenne), which, late in the year, is almost invariahly ergoted, although many of the ergots are so small as to remain concealed within the florets. 'T'he reason that wheat is less frequently affected than rye is because, in the former plant, as soon as its stigma is fertilised by the pollen, it is retracted within the pales, while, in the latter, it remains h inging outside them. Hence we see a suniess year is more apt to be one in which wheat is ergoted than any other, even a rainy one. It is a curious fact that some grasses which do not in this country usually perfect their fruit, are, nevertheless, very prone to be ergoted. The common reed (Phragmitcs communis) is a case in point, and is the probable source from which the whents in the fens become infected. Twitch-grass (Triticum repens) is another instance.

In the fen-district, every year a cortain amount of ergot occurs in the wheat; but sometimes, as in 1879 , it is very abundant. In the lattor year, most of the samples from this district which were offered in the King's Lynn market contained ergots. These, of course, wero but a small proportion of the numbers which originally occurred in it the improved processes of threshing and dressing having eliminated all those ergots which were either larger or smaller than tho whentkerne!s. For this reason, there is not much fear of the general public suffering any ill-effects from this cause. Still such a thing is within the bounds of possibility. There is, lowever, a pretty numerous class to which this does not apply, namely, to the agricultural labourer, who often subsists for many weeks during the winter upon corn which his family have gleaned after the harvest. The total amount of this gleaned corn in the possession of each family, never being very large, it is threshed and dressed by the labourers themselves in tho most primitive manner. It is then sent to the miller to be ground by him, and returned to the family for their winter's consumption. In appearance, a wheat-ergot is very similar to a rye-ergot, but shorter and stouter. They are often mistaken by farmers and millers for the excreta of mice or rats.

With regard to the action of ergot in producing abortion, there is one point which has long struck me; namely, that a pregnant person or animal, by taking a number of small doses extended over a considerable time, is quite as likely to abort as, and perhaps cven more so than, after a single pretty large dose. If the uterus be thrown into a chronic state of contraction, however slight this may be in degrec, it is obvious that the blood-supply to the placenta will be more or less intcrfered with. This may be, at the same time, accompanied by trivial localised separations, so small in themselves, that, when the immediate effect of each dose passes off; the placenta itself is not de. tached, but sufficiently numerous, by their continued repetition, to in flict serious if not fatal injury upon the fatus. Short of this, how ever, it is obvious that the contraction of arterioles, sharactcristic of the action of ergot upon the animal economy, must necessarily imperil the vitality of the embryo in any stage of its existence. This is borne out by what occurs to the flock of pregnant ewes. Here the animals become ergotised, not by a single large dose, but by continually ingesting small ones, principally from rye-grass, which is constantly ergotised in pastures, but especially upon road-sidec. The same is even more strikingly shown in the case of cattle, where the animals are much larger. Often, in these cases, the fotus is not expelled at once, but is so injured that it subsequently dies, and is expelled at a later period.

\section{NOTES ON STROPHANTHUS (HISPIDUS).}

BY J. LINDSAY PORTEOUS, M.D., F.R.C.S.Ed., Pathhead, Fife.

Ar the annual meeting of the British Medical Association in Cardiff Professor Thomas Fraser, of Edinburgh, read a most instructive and interesting paper on "The Actions and Uses of Digitalis and its substitutes, with special reference to Strophanthus (Hispidus)." Dr. Fraser says that the pharmacological action of strophanthine is as a muscle-poison; that it increases the contractile power of all striped muscles, and renders their contractions more complete and prolonged. As to the heart, he says, "the systole is increased, and its contractions are slowed by small doses. It is paralysed in a condition of rigid systolic contraction by large doses." It also increases secretion of urine, and reduces temperature.

Having in my practice a considerable number of cases of cardiac disease, and finding that digitalis did not agree with all my patients, I was anxions to try the effects of this medicine, which had proved so beneficial in the cases of Dr. Fraser. Through his kindness I obtained a small quantity, and I give notes of three cases where I used it; and I an only sorry that the notes aro not fuller; but we all know the difficulty there is in taking careful and correct rezords in private practice.

Case 1.-Mrs. W., aged 38 , of florid complexion, rathicr thin, wife of a factory-worker, stated that she had a severe attack of rheumatic: fever three years ago, and had been troubled with shortness of breath and palpitation ever since. During the night, she had frequently to start up with " a feeling of choking for want of breath." She had been treated by several medical men, and received digitalis from all, which gave temporary relief. On November 12 th, 1885 , she was confined, and although the labour was rapid and easy, it gave me a 
good deal of anxiety, knowing the state of her heart, as indicated by a very marked mitral bruit and a very feeble pulse. Her feet and ankles were much swollen. Her prilse, half-an-hour after the confinement, was, as nesr as I could count, 160 per minute. I ordered her fifteen-minim doses of tincture of digitalis every four hours. This gave her a certain amount of relief, as, eight hours after labour, the pulse was 130 per minute. Her breathing, however, was still very high, 48 per minute. I continued this treatment till the $22 n d$, only changing the time of giving the digitalis from every four hours to every six hours. At bedtime of this day, I gave her a dose of four minims of tincture of strophanthus. On the 23rd, she told ine she had a better night, lying down for one hour and three-quarters. Her pulse was 100 , and very weak; respiration, 30 . The fect and ankles were still swollen; her urino was scanty and thick. I ordered a dose of four minims of tincture of strophanthus immediately, to be repeated in the evening. On the 24th she had slept nearly three hours. Pulse, 108 ; respirations, 26 . The urine was more copious and paler. The same dose of strophanthus was ordered thrice daily. On the 25th she had been restless up to 2 A.M., but after that slept soundly till 7 A.x. Pulse, 102 ; respiration, 22. On the 26 th, she had slept from 11 P.M. till 6 o'clock this morning, lying down all the time. Pulso, 98 ; respiration, 19 ; urine was more abundant and clearer. On the 27th, she had slept the same time as on the previous night; she might have slept longer, but was disturbed by her husband going to work. She had been sitting by the fire for four hours the previous evening, and felt none the worse for it. Pulse, 94 ; respiration, 19. She passed a gool quantity of urine of an amber colour. She was still taking the same dose. On the $28 \mathrm{th}$, when I visited her at 10 A.M., I found her washing her baby. She said she had been up most of the previous afternoon. She told me she had not felt so well for over two years. Pulse, 90, firm and steady ; respiration, 19 . On the 30th, she said she was quite well and able for her household duties. Pulse, 80, strong and firm. She was very anxious to continue the medicine, as she said it had "made life more happy."

I have seen her frequently since the last date, and on December 23rd found her hale and hearty.

CAsE Ir.-Mrs. F., aged 48, thin, pale, and nervous, stated that she had been treated for angina pectoris for years, and, during the last five or six years, had had almost daily attacks of violent palpitation. During nearly the whole of this period, she had taken digitalis. On November 27 th, at 4 P.M., I was asked to visit her, as she was thought to be dying. I found her, propped up by pillows, pale and pulseloss. The heart's contractions were so rapid, that I could not count them. Respirations were 40 por minute. She complained of great pain over her heart, and pressed her hands over it "to prevent it from being torn asunder." She had, before my arrival, taken two doses of tincture of digitalis within four hours, but no relief followed. I ordered her a four-minim dose of tincture of strophanthus, to be taken immediately, and repeated at 10 o'clock, and again at 8 A.s. At 12 noon of the 28th I found her much calmer; the fear of impending dissolution had left her. Her pulse was 110; respiration 24. She had slept well from 2 A.M. to 6 A.M. Her urine was scanty, and rather dark. I ordered her 6 minims of tincture of strophanthus thrice daily. On the 29th, she felt faint during the early morning, and took some salvolatile. When I saw her at 11 A.M., her pulse was 92, respiration 20. Her face was rather flushed. She had passed more urine, an. the bowels had acted. The doses of tincture of strophanthus were continued. On the 30 th, at $11 \mathrm{~A}$. M. pulse 120, respiration 20 . The pulse was firmer than I had ever folt it. She, however, felt weaker, probably due to an attack of diarrhuea during the night. On December 1st, at 10 A.M., diarrhıra was still present; also nausea and vomiting. She said that, shortly after each dose of the strophanthus, she vomited, and her heart beat rapidly for about an hour; pulse 105 , respiration 20. On December 2nd, her pulse was 105, respiration 20 . She still had diarrhœa, nd vomiting and felt very weak. On December 3rd, at 10 A.M., she had sickness and romiting, with diarrhoea. ordered bismuth, dilute hydrocyanic acid, and lime-water; pulse 120 . On December 4 th, she was still sick, but not vomiting ; pulso 120 . She had only taken one dose of strophanthus since yesterday morning. stopped the strophanthus, and ordered fifteen-minim doses of tincture of digitalis every six hours. On December 5th, at 12 at noon, she felt nuch better; the nausea, vomiting, and diarrhcea had ceased. She slept well during the greater part of the night; pulse 88 . She felt pretty well during the 6 th. At 8 A.M. on the 7 th, the patient said her pulse suddenly rose to 130 . She took 15 minins of tincture of digitalis, and at 11 A.M. felt much better ; pulse 110. I ordered (as suggested by Dr. Fraser) 5 minims of tincture of capsicum, with 6 minims of tincture of strophanthus, at bedtime. This was taken, and on the 8th the patient said that shortly after taking the dose, which did not cause sickness, the pulse rose to 140 ; but fell to 98 , at which I found it, very firm; there was no sickness, aud no diarrhoes. I reduced the dose to $2 \frac{1}{3}$ minims. On December 9th, there had heen no rise of pulse, and no sickness; pulse 98. On December 10th, she took two four-minim doses; after each dose the pulse had gone up to 140. On the 11 th she refused to take more, as she felt weak after the rise of pulso.

CAsB IIr. - R. W., aged 7 years and 9 months, was said by her mother to have suffered from breathlessness and palpitation very much for three months, but for some years she had been very easily excited and startled. On November 15th, I was callel to see her. Her feet and face were swollen. There was a soft mitral murmur. She was propped up in bed, and had been unabletolie down for several days ; pulse 142, very weak. The urine was scanty, of porter colour. I ordered tincture of digitalis, in ten-minim doses, thrice daily. Under this treatment, the swelling of the face and feet was much reduced; the quantity of urine wasslightly increased, but not until the 22nd was she able to lie down. After this date, until the 27 th, she was able to get a sound sleep in the recumbent position, and the urine was more copious, and clearer. On the $28 \mathrm{th}$, at 10 A.M., when I visited her, I found that she had been very restless and breathless during the previous night, and had again to take to her chair, the dyspnora being so great. Her look was anxious, and she complained of pain in the region of the heart. Her mother stated that she was very hungry in the evening, and probably had eaten too much; pulse 140, respiration 30. No urine had been voided for twenty-four hours. I ordered minims of tincture of strophanthus three times daily. She had only one dose of the medicine on that day, and shortly afterwards had a copious flow of urine, lighter in colour. At 9 o'clock on the 29th, she had another dose of the stropisanthus. At 11 A.M., when I saw her, the pulse was very feeble, and too fast to be counter. The heart's contractions were very irregular and rapid; respirations, 48 per minute. She had a very anxious, terrified expression. On the 30th, she was easier; pulse 108 (firmer), respiration 48. There was a larger quantity of urine; the bowels wero rather loose. December 1st, pulse 112, respiration 40. She had passed only half a pint of urine in eleven hours. On December 2 nd, pulse 120 , respiration 50 ; the pulse was firmer ; the urine was still scanty and dark. On the 3rd, she иas still taking the strophanthus three times daily; pulse 116, respiration 58. She had a short, dry cough. No urine had been passed for sixteen hours. On the 4 th, pulse 10, respiration 40 . She had only passed urine once in twenty-four hours. I reduced the quantity of strophanthus to $2 \frac{1}{2}$ minims, but ordered it every six hours. On the 5th she was easier; pulse 98, respiration 30. A much larger quantity of urine was passed at $8 \mathrm{r}$.M. of the 4 th than she had ever passed at one time since she became so ill. The same dose of strophanthus was continued. She slept well on the night of the 5th. She breathed more easily on the 6th, and voided urine three times in the night ; pulse 98, respiration 28. On the 8th, pulse 98, respiration 26. The bowels were acting twice daily. The skin was moist, and a good quantity of urine was passed. On the 9th, pulse 100, respiration 26. The medicine having been finished, the bowels did not act ap to last night; but on providing some more, and giving a dose, the bowels acted three hours afterwards. The swelling was entirely gone. On the 11th, she passed plenty of urine. The dyspnoca was quite gone. She was very cheerful and happy ; pulse 90 , respiration 22. Up to Decomber 23rd, I saw her several times. Her pulse had always kept below 92. She was able to play with the other children, had a good appetite, and seemed much stronger. For two or three days she was without the strophanthus, and the only difference was that her bowels became costive; but the pulse remained firmer, and there was no return of the swelling or dyspnnea.

REMARKS. - In all of those cases I have recoriled, tincture of strophanthus decidedly increased the flow of urine. It likewise caused a certain amount of moisture over the surface of the body. Both of these actions Professor Fraser has noted, but he makes no mention of its power of relaxing the bowels. But this it undoubtedly did in all of the cases in which I have used it. It also markedly made the pulse firmer, although, as has been shown, it raises it for a short time after it has been taken. In Case 2, that of Mrs. F., it certainly showed its toxic effects, when it made her purge and vomit, although the close was as small as $t$ minims. She must have been exceedingly susceptible to its poisonous powers.

I am inclined to think that the dose of the tincture prepared by Professor Fraser should, to begin with, not exceed 3 minims. Where I gave more, the pulse invariably rose at first, but it was no loubt firmer.

Strophanthus, if carefully used, is destined to hold a foremost place amongst our remedies for controlling the heart's actiou, but, like other romedies, will not suit every pationt. 